\title{
The uncertainty of suffering
}

Preston Williams, BA

School of Medicine, Texas A\&M Health Sciences Center, Dallas, Texas grew up in a black and white world. Life was easy and the path was clear. My parents had straightforward answers to all of my existential questions and "uncertainty" wasn't even part of my vocabulary. Medicine further embodied this principle in my mind. Strep throat was treated with antibiotics, Tommy John surgery was a minor speed bump after a torn ulnar collateral ligament, and physicians were the superheroes who made it all happen. I thought that people died only because they didn't make it to the hospital in time. If they arrived there alive, everything would be okay. I pretty much believed this my whole life —until I met Ms. P.

I met her on my first day in the multiple sclerosis clinic. She was a kind, middle-aged woman whose life had been train-wrecked by primary-progressive multiple sclerosis. Confined to a motorized wheelchair, her tired expression revealed her suffering even though she was in no obvious distress. We exchanged pleasantries and then I asked about her symptoms. She began by half-heartedly complaining of growing memory problems, increasing episodes of vision loss, and greater upper-extremity weakness. She relayed her ever growing list of disabilities and described the game of Russian roulette her immune system played with her myelin, seeming to be above it all. But as we continued talking, she began to weep. Through gasps, she told us how she "knew" the Multiple Sclerosis Society had discovered the cure for her condition, but this cure had been withheld so companies could profit from expensive medications. She lamented her disease and how it had ripped her life from her. It had taken away her gardening and horseback riding and shattered her hope of playing with her future grandchildren. She said she was depressed almost every day and implored us to explain why this happened to her. The problem was, I didn't have a clue. I had no mental category for this level of random suffering. I held it together in the room as I processed all that was happening, but once we left, my whole worldview came crashing down. I began to realize that life was not all solid ground; some problems didn't have good answers. There was no explanation, and there was no cure. Medicine didn't have a magic bullet for Ms. P. All we could do was slow down her symptoms and take front-row seats as the disease that we researched would break her down and take her life.

A few semesters later, while playing in a baseball game, my foot caught hold of someone else's shoe and I fell backward, landing directly on my head. I suffered a concussion but was too caught up in the moment to realize what happened. I had no idea I needed to rest and received two more concussions over the next 3 weeks. Ironically, the main symptom that bothered me was not the constant headache; it was the overwhelming feeling that something was very, very wrong. I no longer felt comfortable being alone and believed the unrelenting sensation was due to problematic thoughts racing through my mind. I thought I was going crazy. After seeing a psychologist, several neurologists, and undergoing a plethora of tests, we finally pieced together what happened and arrived at the diagnosis. But as I went from appointment to appointment and tried medications, physical therapy, and a host of other treatments, I began to see the writing on the wall. My psychologist told me, "I'm going to help you learn how to be comfortable being uncomfortable." I immediately bristled at the thought that my condition might be "incurable," but I slowly began to accept that though it was far less lethal and physically debilitating, my situation was similar to Ms. P's: there would be no silver bullet.

Because of my upbringing, I trembled at the thought of anything less than clear-cut answers, and the path of trying to find comfort in the middle of my discomfort was a long and tumultuous journey. Slowly but surely, I began to feel at ease with my mind and at home with my affliction, but I realized that a large part of my relief was having someone to work through my distress with me. My psychologist reached out when I was at my lowest and showed me that I had

Corresponding author: Preston Williams, BA, School of Medicine, Texas A\&M Health Sciences Center, 1210S. Lamar St. \#1237, Dallas, TX 75215 (e-mail: pwwilliams5@exchange.tamu.edu)

Received October 26, 2019; Revised December 18, 2019; Accepted December 23, 2019. 
someone committed to walking through this with me. I learned that the art of medicine was not limited to figuring out the right way to combine treatments for maximum benefit; often, the physician-patient relationship itself was a major part of the healing.

In my interaction with patients and my own personal experience with suffering, I have learned that life is cruel and the world can be maddening. Affliction befalls everyone and is often unrelenting, but it doesn't have to conquer us. In the face of tragedy, we can connect with each other and walk with each other, learning to find comfort amidst uncertainty. I would love to be the hero and cure everyone with a simple solution, but that is not always in the cards for us as human beings. Sometimes we do have the answer, and those are the greatest moments. But other times, affliction wounds beyond our best treatment's ability to cure. Even so, as physicians we must heal even when medicine doesn't have all the answers.

Just 3 days ago, I had to sit with a patient as she discovered she had an ectopic pregnancy. There would be no baby shower, no watching her longed-for child grow up. It wasn't okay. It will never be okay. But we were in it together. Life is hard, but real love can heal our spirits in mysterious ways. Not the sappy, romantic feeling of love, but the loyal, compassionate love that says "I'm with you; you are not alone." Medicine can't always stop the body from breaking down, but love can bring us peace and help us be at home even in a world full of gray.

\section{Reader comments}

\section{$\mathrm{Hi}, \mathrm{Dr}$. Roberts,}

Just a note to say that I enjoyed "Facts and Ideas From Anywhere" while this sweetie (Figure 1) didn't feel like sleeping last night. A great edition as always.

-Stacy GuReVitz Beal, MD

BUMC Pathology Resident, 2009-2012

stacygbeal@ufl.edu

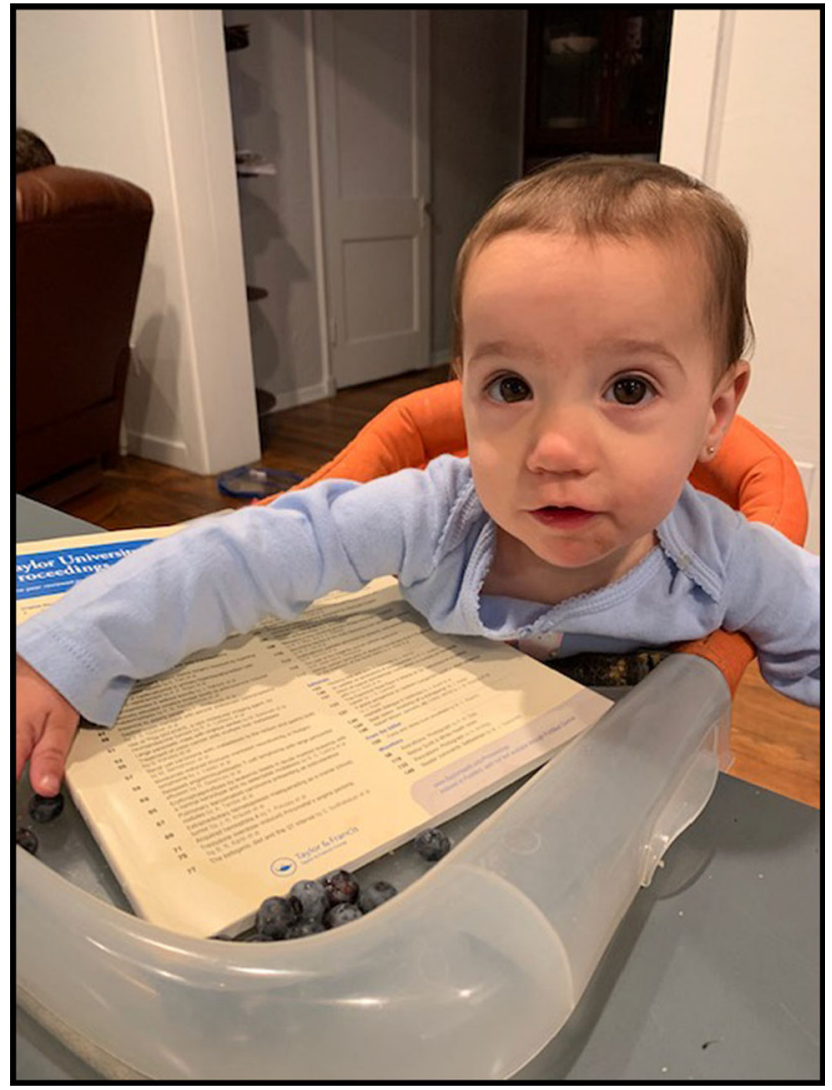

Figure 1. Dr. Beal's child checking out Baylor University Medical Center Proceedings. 